\title{
Theoretical aspects of substantiating the efficiency of economic decisions aimed at development of high-rise housing construction
}

\author{
Ekaterina Nezhnikova ${ }^{1, *}$ \\ ${ }^{1}$ Peoples' Friendship University of Russia (RUDN University), Miklukho-Maklaya Street, 6, \\ Moscow, 117198, Russia
}

\begin{abstract}
The article is devoted to theoretical aspects of substantiation of efficiency of economic decisions in the field of high-rise housing construction. It presents stratification of population according to various parameters and on this basis a target audience of solvent consumers is identified, at which government and developers should aim during design and implementation of high-rise housing construction projects. The currently growing interest of investors and developers in high-rise housing construction in the large cities of Russia is substantiated. Mixed feelings of solvent citizens, that are willing to improve their housing conditions, to living and working in tall buildings is figured out. When substantiating the efficiency of economic decisions aimed at the development of high-rise housing construction, it is suggested to take into account qualimetricly not only local economic and natural climatic conditions, but also the specifics of constructional and space-planning decisions of the project.
\end{abstract}

\section{Introduction}

The relevance of this study is dictated by the contradictory nature of economic interests, goals and expectations of participants in the construction of high-rise residential and administrative buildings, on the one hand, and the economy of business processes of construction and operation of high-rise building products on the other hand. In this regard, it should be noted that the growing interest of investors and developers in the subject of high-rise housing construction is now largely determined in the large cities of Russia by the high cost of land plots in the historical and administrative centers of Russian megapolises.

Therefore, justifying the relevance of the topic of high-rise housing construction, it should be emphasized that the most important criterion for assessing the effectiveness of the state housing policy is, primarily, the effectiveness of the participation of government authorities in addressing the emerging socio-economic and regulatory problems. This is due to the fact that care of the authorities of any country about the well-being of its citizens is most clearly manifested in the solution of the housing problem.

Though, this social problem for any society is permanent and not saturatedsince the need for the amount and quality of housing is not static, but dynamic. At the same time, the

\footnotetext{
* Corresponding author: katnej@mail.ru
} 
numerical values of indicators of the level of housing needs, as well as the type of organizational and economic mechanism for their satisfaction, directly depend on the financial state and priorities of national economies. Thus, it is important to find the balance between the technical requirements of insolation and the economy of the project to be relevant.

\section{Methods and results}

It should be noted that in actual practice, the state usually performs its functions through the development and implementation of measures of socio-economic policy. Moreover, the state in a market economy is not just one of its main subjects, but, first of all, the economic and political center of influence on the country's socio-economic development. Therefore, the primary function of the state should be the regulatory impact (implementation) on the subject-object structure of the entire system of the national economy in modern Russian conditions, including the housing sector.

Qualitative steps in the theoretical development of economic science are formed in the case when the quantitative accumulation of knowledge about certain aspects of the subject of research is generalized, systematized and examined by researchers in the interrelation and interaction between those knowledges. Consequently, the construction of a new subordinated system of economic categories, relations and connections between them requires the systematic nature of the method of scientific research. At the same time, the system approach does not exclude the analysis of individual elements of the system, since each of them is an independent system and has its own characteristics and distinctive properties.

In this regard, the authors share the ideas of Z. Bauman, who has identified and scientifically proved the strengthening of uncertainty in life in recent decades and the increase in the imbalance in the life of socioe-conomic relationships, the growing uncertainty about their future and the decline in their safety. The most promising and effective is the "welfare state" approach, the essence of which lies in the targeted, primiraly, economic development of the country. The main criterion for assessing socio-economic policy measures is the quality of life of the weakest of its members, which is also a moral standard of society [1].

Therefore, according to the results of studies by a number of foreign and Russian scientists and experts, the efficiency of social and economic policies in the field of high-rise housing construction directly depends on the financial state of national economies and the level of solvency of citizens, who are in need to improve their housing conditions.

In this regard, it must be emphasized that equality of people is the cornerstone of "social humanism", but human dignity is primary for this principle. At the same time, "social humanism" admits stratification of population according to the income: it allows a strong and well-off citizen to freely realize themselves, whereas weak and poor are guaranteed social support and care.

In the actual practice of developed countries, the implementation of this principle makes it possible to harmonize the distribution of results of economic activity and so the relationship between the state and social groups. However, according to the obtained data [2], the main priority, as it used to be previously, stays to increase the volume of economyclass housing with the implementation of the new editions of the federal target program "Housing". Though, the issues of increasing the height of residential buildings, as well as their comfort and quality, have not defined previously and do not currently define these programs.

It is necessary to form and develop highly qualified human capital assets [3], which are able not only to generate creative ideas, but also to promote them further to the market in 
order to create an innovative economy. Therefore, it is necessary to fulfill a number of conditions:

- raise the standard of living of the population (eradicate poverty, increase the income of the population, create new jobs that are required for the establishment and development of the innovative economy);

- create and provide housing conditions that meet the requirements of environmental friendliness and quality, promote the formation of a new type of person, develop creative potential.

In the opinion of N.E. Tikhonova [4], the economic status of individuals is determined by the level of income and the possession of property (real estate, durable goods, savings). She rightly asserts that the problem of real estate at the disposal of the population has a special status:

1. this is the most expensive property that citizens have (most of them are not able to buy housing independently);

2. residential real estate is a criterion of well-being, accumulated throughout life, by a specific family;

3. the nature (level) of occupied housing allows one to refer to the rich, and others to the poor [5].

So, regarding housing conditions, this should be housing of different storeys (including high-rise buildings, low-rise buildings, etc.) and high quality level meeting the accepted standards, implemented with the use of environmentally friendly materials and technologies as well as be located in ecologically favorable areas.

Based on the research results of some foreign and Russian scientists and experts, the authors believe that such housing can be provided to citizens participating in the formation of the innovative economy system on a leasehold basis with subsequent repurchase into property or sold into property on preferential terms in accordance with existing contractual relations. At the same time, it should be emphasized that this dwelling, although it should meet the strict list of criteria, is not housing for the rich segment of the population, as it is oriented toward the middle class.

In this regard, the authors do not agree with $\mathrm{T}$. Veblen that comfort and luxury naturally belong to the idle class [6], since the results of the research indicate that quality and ecological comfortable housing conditions and a decent standard of living of the population are able to make breakthrough in the Russian economy. That is why it is necessary to create a strong middle class in Russia, which became the basis of the economies of many developed countries. It is the middle class that takes an active part in the life of the country and drives the national economy and the basis of budgetary tax replenishments, it is a certain guarantor of the stability of society and the economy. The share of the middle class in the population should not be less than the total share of groups whose social status is below the status of the middle class. Individuals for whom these characteristics have the highest expression are the groups located on the social ladder above the middle class (the aristocracy, the elite).

The study of theoretical aspects to substantiate the efficiency of economic solutions for the development of high-rise housing construction would be incomplete if the research results of T.I. Zaslavskaya were not considered [7]. In particular, she suggested another stratification and social structure of Russian society, which includes:

- - the ruling elite (the top of Russian society, whose share in the population is a fraction of a percent, while the resources under their control are comparable to the resources of the rest of society);

- - the top stratum (sub-elite) - owners and managers of large enterprises, banks, companies, generals of law enforcement agencies, etc .; 
- - the middle stratum (not very massive socially heterogeneous): middle-ranking bureaucracy worker, high-ranking officers, small and medium entrepreneurs, directors of small state enterprises, private sector managers, highly-qualified and high-demand professionals;

- - the base stratum (the major part of the society, $2 / 3$ of the employed in the economy and more than half of all Russians): the majority of ordinary professionals in mass occupations (engineers, teachers, doctors), clerks, industrial workers, peasants, farmers, trade and service workers;

- - the lower stratum (narrow and powerless stratum): the least qualified part of workers and employees, persons without occupation, chronically unemployed, the majority of pensioners and disabled people with minimal means of living;

- - underclass (quite extensive): its representatives are virtually excluded from society, they live according to their own norms and rules, that are often contrary to morality and law: thieves, bandits, racketeers, prostitutes, beggars, homeless people, vagabonds, street children, alcoholics and drug addicts living in families [7].

Thus, the suggested stratification should be based on the base stratum of society and partly on the middle class in the development of expensive high-rise housing construction.

In this regard, in order to obtain own independent results, a survey was conducted aiming at identifying the level of housing and social conditions of the population to get an objective picture of the criteria for selecting housing construction for groups of consumers with different income levels and their housing preferences.

The following group of factors, that are important to identify the respondents' status, according to the Varimax method, can be used:

- associated with the occupation and features of a person's market position;

- associated with the region and residency, reflecting the state of the labor market;

- associated with the ascriptive characteristics of a person (age, health, sex);

- associated with one's habit (the presence of individualistic attainment attitudes (conformist-paternalistic), mobility of the psyche, residency in the initial period of socialization, related to the possibilities to get accustomed with the norms of urban / rural culture and influencing the trajectories of the subsequent mobility of a person);

- associated with human behavioral strategies (the availability of secondary employment, the acquisition of a new specialty, a change of employment, etc.).

The results of the authors' studies [8] indicate that the exacerbation of the housing problem was influenced to a large extent by the stratification of the population by income level and the emergence of high and middle class Russian citizens with new needs, not only for quantity but also for the quality of the acquired residential real estate objects.

In particular, the results of the conducted sociological survey of housing needs of Russian citizens represent that high quality and environmental safety of residential buildings (including high-rise buildings) - new housing consumer preferences - have become the life priority for a large number of Russian citizens $(89.1 \%$ of number of respondents), regardless of their gender and age, level of income and education, occupation and social status.

Dwelling on the results of the survey, the attitude of solvent citizens to the topic of high-rise housing construction is ambiguous. So, along with respondents, who support living in the "skyscrapers" and only note the advantages (spectacular visualization - a panoramic view from the windows of apartments or offices, the effect of "hovering" above the ground, prestige, image, etc.), many respondents paid attention to domestic inconveniences and the high cost of buying and maintaining such apartments or offices (the entrance to the apartment / office and their exit is accompanied by a long wait for a passenger or cargo elevator, the high cost of rent, cleaning and renting parking spaces, no garbage disposal, etc.). 


\section{Conclusion}

It has been established that the trends in the development of the housing sector, that are relevant and reasonable for the recent past and even the present, can not be innitially considered as the only true not only in the long-term, but also in the medium term prospects, since consumer preferences and priorities in the housing market are largely variable and are determined by the not always predictable behavior of its subjects.

Mixed feelings of solvent citizens, who want to improve their housing conditions, about living in high-rise buildings are revealed. So, along with respondents, who support living in the "skyscrapers" and only note the advantages (spectacular visualization - a panoramic view from the windows of apartments or offices, the effect of "hovering" above the ground, prestige, image, etc.), many respondents paid attention to domestic inconveniences and the high cost of buying and maintaining such apartments or offices (the entrance to the apartment / office and their exit is accompanied by a long wait for a passenger or cargo elevator, the high cost of rent, cleaning and renting parking spaces, no garbage disposal, etc.). In addition, many solvent citizens refuse to live and work in high-rise buildings because of psychological discomfort.

Summarizing the above, it should be emphasized that, up to now, both in the world and in Russia, high-rise housing construction does not have a straightforward system of universal and compelling cost indicators that substantiate the efficiency of economic decisions in the field studied in the present paper. Since such decisions are dictated not only by local economic and natural climatic conditions, but also by the specific nature of constructional and space-planning decisions of a particular project.

\section{References}

1. Z. Bauman, The Individualized Society (Polity Press, Cambridge, 2001)

2. E.V. Nezhnikova, Metodologiya formirovaniya novoj gosudarstvennoj ehkonomicheskoj politiki $v$ sfere zhilishchnogo stroitel'stva: monografiya (MAKS Press, Moscow, 2015)

3. S.S. Uvarova, V.S. Kankhva, S.V. Belyaeva, Procedia Engineering 165, 1046-1051 (2016)

4. N.E. Tihonova, Social'naya struktura Rossii: teorii i real'nost' (Novyj hronograf: In-t sociologii RAN, Moscow, 2014)

5. N. Safronova, E. Nezhnikova, A. Kolhidov, MATEC Web of Conferences (2017) doi:10.1051/matecconf/201710608024

6. T. Veblen, Teoriya prazdnogo klassa. Izd. 4-e (Knizhnyj dom «LIBROKOM», Moscow, 2011)

7. G. Taveggia, A. Borboni, C. Mulé, J.H. Villafañe, S. Negrini, International Journal of Rehabilitation Research 39(1), 29-35 (2016) DOI:10.1097/MRR.0000000000000137

8. A. Larionov, MATEC Web of Conferences 106, 09022 (2017) 